\title{
Laparoscopic Total Mesorectal Excision for Rectal Cancer Surgery
}

\author{
Jacques Marescaux Francesco Rubino Joel Leroy \\ IRCAD - European Institute of Telesurgery, University Louis Pasteur, Strasbourg, France
}

\author{
Key Words \\ Rectal cancer surgery - Laparoscopic total mesorectal \\ excision - Total mesorectal excision, definition and \\ principles
}

\begin{abstract}
The introduction of total mesorectal excision in the early 1980 s has improved local control and survival in patients with rectal cancer. Laparoscopic resections for colonic malignancies are gaining acceptance in the light of the recent evidence of oncologic adequacy from randomized clinical trials. Technical difficulties and the difference in the natural history of the disease have excluded rectal cancer from major clinical trials comparing laparoscopic to conventional rectal surgery. This review examined the feasibility, safety and oncologic outcomes of reported laparoscopic total mesorectal excision for surgical treatment of operable rectal cancer.
\end{abstract}

Copyright (c) 2005 S. Karger AG, Basel

\section{Introduction}

Local control and survival after surgical treatment of rectal cancer have been significantly improved by the introduction of total mesorectal excision (TME), first described by Heald et al. [1] in 1982. Consistent findings in several independent reports have showed that TME achieves a considerably lower local recurrence rate [2], longer survival [3], better functional results [4] and also a reduction in the need of abdominoperineal resection [5] compared to conventional surgical techniques. Most recent series of open TME documented a local recurrence rate of $4-8 \%$ and cancer-specific survival rates of $70-80 \%$ at 5 years $[6,7]$.

Laparoscopic techniques have gained popularity due to the advantages of improved recovery and better cosmesis. Recently, several prospective randomized multicenter studies have shown that the laparoscopic approach is a safe option for the treatment of colon cancer since its oncologic outcomes compare favorably with those of conventional open colectomy $[8,9]$. However, patients with rectal cancer have traditionally been excluded from these trials because of the complexity of the techniques required in both open and laparoscopic procedures to achieve TME with sphincter preservation.

The purpose of this review was to examine operative data, short- and long-term oncologic outcomes of reported series of laparoscopic TME.

\section{Definition and Principles of TME}

TME has been widely adopted as the standard technique for curative resection of cancers of the lower $10 \mathrm{~cm}$ of the rectum. The surgical technique includes routine excision of the intact mesorectum by precise sharp dis-

\section{KARGER \\ Fax +4161306 1234 E-Mail karger@karger.ch} www.karger.com
Prof. Jacques Marescaux

IRCAD - European Institute of Telesurgery

1 Place de l'Hôpital

FR-67091 Strasbourg (France)

E-Mail Jacques.Marescaux@ircad.u-strasbg.fr 
section in the areolar tissue between the visceral and parietal layers of the pelvic fascia. By this way, micrometastases that may lie in the mesorectum are removed en bloc with the rectum and the tumor [10]. Pathological studies by Reynolds et al. [11] have indeed emphasized the widespread distribution of metastases within the boundaries of the mesorectum strongly supporting the need for a complete resection of the mesorectum with uninvolved circumferential margins. If the dissection is carried out correctly into the avascular plane between the presacral fascia and fascia propria, which invests the mesorectal fact, the operation can be performed sparing pelvic nerves [12].

Application of the TME technique has been reported to reduce local recurrence rates from 47 to $11 \%$ in some series [13] and to improve long-term survival [14, 15].

\section{Laparoscopic Approach for TME}

Laparoscopic techniques have been shown to offer several advantages over their conventional open counterparts, including earlier return to bowel function, reduced postoperative pain, shorter hospitalization and better cosmesis [16-19]. However, many surgeons have been reluctant in adopting a laparoscopic approach for malignant diseases for fear that such a technique could result in incomplete cancer clearance and consequent increase in local or abdominal-wall recurrence rate and reduced overall survival. Recently, at least three large randomized trials $[8,9,20]$ comparing laparoscopy and laparotomy for colon cancer have been reported. Consistently, these studies reported at least similar rates of local recurrence and long-term survival with both approaches, demonstrating the safety of laparoscopy for colonic malignancies. Generally, these studies did not include TME for rectal cancer, as this procedure is deemed as more technically demanding than laparoscopic colectomy. However, several series have been reported in recent years, with encouraging results.

These series have documented the technical feasibility of laparoscopic TME, although operating time seems to be longer than the time required for a laparotomic TME. In spite of this longer time for surgery, in several series, laparoscopy seems to retain the classic advantages of minimally invasive surgery also for TME, that is, reduced length of hospitalization and less postoperative pain.

Abdominal perineal resection is particularly amenable to laparoscopy because the specimen can be retrieved through the perineal incision, thus obviating the need for any abdominal incision other than the stoma site and for anastomosis. The benefit of laparoscopy in case of abdominoperineal resections are therefore more pronounced than for laparoscopic anterior resections, where the need for an anastomosis and the retrieval of the specimen require a small abdominal incision in the pubic area.

Laparoscopic anterior resection with sphincter-saving TME is more technically demanding, especially in case of low anastomosis, due to technical limitations in using current laparoscopic staplers deep in the pelvis and the risk that the distal resection line in the low rectum might not result exactly perpendicular to the longitudinal axis of the rectum, but at an acute angle to this axis.

At our institution, the technique of laparoscopic TME has been standardized as follows [21]. Colorectal mobilization, vessel ligation, transection and anastomosis are performed entirely laparoscopically. Five to six trocars are used for the procedure. The size of the trocars is between 5 and $12 \mathrm{~mm}$. To avoid excessive mobility of the trocars during the procedure, a suture is sometimes used to anchor the trocar to the abdominal wall. The dissection is begun by high ligation of the superior mesenteric artery at its origin from the aorta. If a significant ascending left colic artery is encountered, an effort is made to preserve it while completing a thorough lymphatic clearance of all the lymph nodes at the base of the inferior mesenteric artery. The rectum is then mobilized as far down as possible on its posterior and right lateral surfaces, before opening the anterior rectal space from right to left, extending from Douglas' pouch. Lower rectal dissection is performed after freeing the lateral attachments of the sigmoid colon, followed by the rectum, on its left lateral and posterior surfaces, thus allowing complete upward rectal mobilization. The dissection is then pursued by alternating right lateral, left lateral, anterior and posterior dissection down to the pelvic floor.

The dissection of the mesorectum is performed under direct vision using sharp dissection techniques and minimal use of low current intensity electrocautery or Ligasure $^{\circledR}$. It is carried out between the parietal and visceral planes of the pelvic fascia. A deliberate attempt is made to identify and preserve the components of the pelvic autonomic nervous system, namely the superior hypogastric nerves, the autonomic branches of S2, S3, and $\mathrm{S} 4$ as well as preservation of the pelvic autonomic nervous plexus. The rectum is excised completely enveloped within the visceral pelvic fascia. The resected specimen is placed in an extraction bag (Endocatch II, USSC, Norwalk, Conn., USA) and extracted through a small supra- 
pubic Pfannenstiel-type incision. The incision is additionally protected from direct contact with the specimen by the use of a plastic wound protector. In case of sphincter preservation, the anastomosis is performed using standard double stapling techniques or by coloanal handsewn anastomosis. A rectal washout is not routinely performed before transection but a thorough irrigation of the pelvis is carried out following transection of the rectum. We now routinely perform an ileostomy to protect the anastomosis.

\section{Morbidity of the Laparoscopic Approach for Rectal Cancer}

The largest reported series of laparoscopic TME shows an overall mortality rate of about $1-2 \%[21,22]$ which compares favorably with the $3-8 \%$ range reported in open surgery [23]. Postoperative morbidity of laparoscopic TME ranges between 18 and 37\% [24, 25]. The conversion rate ranges widely between 3 [21] and $18 \%$ [24, 26, 27]. Most commonly, conversions become necessary for tumor fixity and doubts about the resectability of the tumor, perioperative bleeding, dense adhesions or inadequate visualization due to obesity [25]. The surgeon's experience however also seems to play a major role.

The most important concern about the technique of TME is the potential increase in the rate of anastomotic leak. Several authors have indeed reported higher leak rates with TME surgery as compared to conventional anterior rectal resections [6-28]. In Heald group's [29] open TME series, the clinical anastomotic leak rate was $11 \%$ whereas an additional $6.4 \%$ was revealed by contrast studies. In the Dutch Colorectal Cancer Group Trial [30] the clinical leak rate was $12 \%$. In general, leak rates after open TME have been reported between 5 and 20\% [31, 32]. Risk factors for anastomotic leakage in the setting of surgical resection for rectal cancer include: male sex, obesity, anastomosis $<5 \mathrm{~cm}$ from the anal verge as well as emergency procedures. To avoid the clinical sequelae of anastomotic leak, many surgeons employ routine fecal diversion by means of a loop ileostomy [28-33]. This has also been our policy in recent years. Some authors also suggest that a side-to-end anastomosis or construction of pouches can prevent this increased risk of clinical leak rates $[34,35]$.

In our reported experience [21] of more than 100 cases of laparoscopic TME, the total leak rate was $17 \%$, but only $65 \%$ of these leaks required reoperation for drainage or diversion. These findings are consistent with those of a similar size study by Morino et al. [22]. The differences in the rates of anastomotic leak in the literature seem to depend on the definition of leak. Whereas some authors indeed report both clinical and radiological leaks, others report only leakages with clinical sequelae, which may underestimate the actual rate of anastomotic dehiscence. Others suggest that the laparoscopic approach may be more prone to anastomotic leaks. Indeed, current stapler design for laparoscopic surgery could play a role. In fact, transecting the rectum deep in the pelvis requires placing the mechanical stapler through the suprapubic port resulting at best in an angled approach to the lower rectum and thus in an unduly long staple line. This puts a longer segment of bowel at risk for clinical leak. With improvement in current instrumentation, the use of roticulating mechanical stapling devices may result in improved ability to apply the stapler at a right angle to the bowel resulting in a shorter rectal stump staple line thus potentially reducing the rectal stump ischemic zone. Immediate alternatives include the use of coloanal handsewn anastomoses in the setting of TME or the application of a TA-30 stapler via a suprapubic minilaparotomy, which could also be used for specimen extraction. At our institute we have recently been making wider use of coloanal anastomosis to minimize the risk of anastomotic dehiscence.

Although there is a theoretical technical limitation in performing the anastomosis with current laparoscopic staplers, prospective non-randomized comparative studies of laparoscopic vs. open TME seem to be consistent in less blood loss, earlier recovery of bowel function and shorter hospital stay with the laparoscopic approach [36, 37]. Overall morbidity seems also to be reduced by the laparoscopic approach [36, 37]. In a case-control study comparing laparoscopic and open TME, Breukink et al. [25] reported $9 \%$ anastomotic leakage in the laparoscopic group vs. $14 \%$ in the open group.

Quah et al. [38] reported higher rates of male sexual dysfunction after laparoscopic-assisted rectal resection compared to the open approach. This complication, associated with the low rate of bladder denervation in their series, indicated the lateral pelvic plexus deep in the pelvis as the most likely site of damage. However, these authors performed completion of rectal dissection in the pelvis via a suprapubic wound incision (open approach) rather than by a totally intracorporeal technique thus possibly negating the benefits of improved laparoscopic visualization of structures deep in the pelvis [39].

Dig Dis 2005;23:135-141 


\section{Oncologic Outcomes}

\section{Radicality of Resection}

Of great concern is whether laparoscopy provides or not an equivalent radicality of resection compared with that of the open procedure. An adequate cancer operation includes suitable margins, adequate lymph node dissection and prevention of spillage of cancer cells into either the peritoneal cavity or the adjacent lumen of the bowel.

To reduce local recurrence rate, an adequate TME must be performed. Unfortunately, most series of laparoscopic TME do not evaluate in detail the oncologic adequacy of the mesorectal excision. In a macroscopic assessment of the quality of mesorectal excision, Bretagnol et al. [27] reported preservation of the fascia recti with the perirectal fat in $88 \%$ of cases after laparoscopic TME, which is an acceptable quality for mesorectal excision. Involvement of the circumferential margin (CMR) of resection is a strong prognostic factor for both local and distant recurrences [40]. A CMR of $<2 \mathrm{~mm}$ is associated with a $16 \%$ risk of local recurrence, whereas this risk is reduced to less than $6 \%$ in patients with margins $>2 \mathrm{~mm}$ [40]. Positive CMR margins have been reported in $7 \%$ of laparoscopic TME by Bretagnol et al. [27], comparing favorably with the $12 \%$ rate in their own open experience. Comparing laparoscopic TME with an open matched group, Breukink et al. [25] also showed similar rates of safe CMR. Overall, using a cut-off of $1 \mathrm{~mm}$, reports of laparoscopic rectal surgery documented positive CMR rates between 0 and $6 \%[41,42]$.

A few studies have compared results for length of resected tumor margins between open and laparoscopic procedures. Lord et al. [43] reported superior recovery of distal margins during laparoscopic-assisted anterior resection for colorectal carcinoma. In a study reported by our group, all patients who had undergone laparoscopic TME had a negative distal margin of resection with a mean of $3.46 \mathrm{~cm} \mathrm{[21].}$

Lymphadenectomy. With regard to adequacy of lymph node dissection, several studies, including randomized trials, have compared outcomes of laparoscopic colon cancer surgery with the traditional open procedure. None of these studies found any significant difference between the procedures in terms of lymph nodes recovered [9, 10, $19,20]$.

The number of resected lymph nodes during TME varies widely. A minimum of 12 lymph nodes is recommended to assess the $\mathrm{N}$ category [44]. Most laparoscopic TME series report lower median numbers of harvested nodes.
However, lymph node harvest may not be used as a good measure of technique adequacy because the number of lymph nodes identified in a specimen depends on the diligence of the pathologist and can be influenced by preoperative radiotherapy [45].

To evaluate the number of nodes left inside the pelvis after laparoscopic TME, Decanini et al. [46] performed laparoscopic abdominoperineal resections on 11 fresh cadavers and then evaluated the mesorectum and pelvic sidewalls, showing no remaining nodes in all cases. Several clinical studies comparing laparoscopic and conventional resections showed comparable node clearance between the two approaches [47].

Local Recurrence. Enker et al. [15] reported a 4\% local recurrence rate following open TME for Duke's B cancers and $8.1 \%$ for Duke's C carcinoma. In an update of his series, Heald et al. [29] reported an overall $6 \%$ rate of local recurrences at 5 years and $8 \%$ at 10 years. In our series of laparoscopic TME, the local recurrence rate was $6 \%$ [21], in accordance with other laparoscopic series and comparing well-published series of open TME.

\section{Port Site Metastasis}

A recent review of 20 laparoscopic colectomy studies performed between 1994 and 1998 found 30 port site recurrences in 2,635 operations for an overall rate of port site metastases of $1.1 \%$, after a mean follow-up of 10-33 months [48]. Randomized clinical trials [8, 9, 19, 50] reporting specifically on port site recurrence did not find any recurrence. Many uncontrolled case series of laparoscopic colectomy reported recently also show a zero incidence of port site recurrence.

We have not witnessed any port site recurrences in our series of laparoscopic TME [21], consistently with reports of others [27]. Results of recent studies and our data are possibly due to the standardization of the surgical procedure along with the use of trocar fixation, minimal tumor handling (no-touch technique), routine use of wound protection as well as specimen bagging. There is indeed a growing body of evidence that port site recurrences in laparoscopic surgery are primarily technique-related rather than an inherent risk of the laparoscopic approach.

Long-Term Survival. In a multicenter study on open TME, Havenga et al. [51] found that 5-year overall survival and cancer-specific survival ranged between 62-75 and $75-80 \%$, respectively. In our experience with laparoscopic TME [21], the overall 5-year survival was $65 \%$ and the overall cancer specific 5 -year survival was $75 \%$, which compares favorably with previously reported results of 
open series. In a series of 144 patients, Bretagnol et al. [27] reported $89 \%$ overall and $77 \%$ disease-free survival at 3 years. However, much of the variation in survival rates between studies can be attributed to differences in the makeup of the study population. Factors such as inclusion of patients undergoing palliative surgery, differing definitions of curative surgery and a different mix of stages may have as much impact on outcome as the surgical technique itself. Patient selection bias as well as postoperative staging bias may in part explain the favorable results in some studies. Inevitably the best assessment of the impact of laparoscopic TME on long-term survival would come from carefully conducted prospective randomized trials.

\section{Possible Advantages of the Laparoscopic Approach for TME}

Consistent evidence from randomized trials has proven that a laparoscopic approach for colon surgery has several advantages including shorter hospital stay, less pain, and decreased analgesia requirements $[8,9,19,20]$. These advantages seem to apply also to laparoscopic rectal surgery as suggested by recent non-randomized comparative studies [25, 36, 37]. Available literature data show that laparoscopic TME may improve short-term outcomes and decrease blood loss [36] while preserving the oncologic radicality of the procedure.

Other potential advantages of a laparoscopic approach to TME may also be specific to the particular anatomy and the technical challenges of operating in a deep narrow space.

The magnification that is offered by the endoscopic camera allows greater precision and better identification of critical structures such as the nervous plexus, significantly aiding in their preservation. This may also explain decreased blood loss as shown by some studies. Furthermore, the ability to perform deep pelvic dissection in full view of the whole operating team will undoubtedly accelerate the teaching of rectal cancer surgery and possibly lead to a better standardization of the surgical procedure. Since laparoscopic surgery allows to monitor and record the differences in operative technique, surgical standardization can be documented photographically and videos used to prove adherence to strict oncologic criteria, which hold importance for quality-controlled studies on the outcomes of adjuvant therapy [7].

Laparoscopic instruments also lend themselves to robotic control better than human hands while video im- ages are well suited to transmission. These features make laparoscopic surgery appropriate for performance even from remote distances [52] enabling an expert surgeon to proctor performance of laparoscopic TME with the potential to blunt the learning curve. Future development of more perfected computer simulated techniques and virtual and augmented reality training systems [53, 54] may also add more potentialities to laparoscopic surgery for rectal cancer.

While the overall cost for the laparoscopic approach has traditionally been higher than its open counterpart, the benefits of early return to work as well as reduced intra-abdominal adhesions could offset these higher costs in the long run.

\section{Conclusion}

A review of current literature data on laparoscopic TME suggests that the standards of rectal resection for cancer are achievable laparoscopically. Results of several studies are consistent in showing that laparoscopic TME is safe and feasible in expert hands and could potentially offer all the benefits of a minimally invasive approach and achieve short- and long-term results that compare favorably with conventional rectal surgery. Furthermore, the possibility to have the procedure documented photographically and by real-time video hold a great potential for the teaching of rectal cancer surgery as well as to prove adherence to strict oncologic criteria. Both such advantages may lead to a better standardization of the TME technique. 


\section{References}

1 Heald RJ, Husband EM, Ryall RD: The mesorectum in rectal cancer surgery - the clue to pelvic recurrence? Br J Surg 1982;69:613616.

-2 Enker WE, Laffer UT, Block GE: Enhanced survival of patients with colon and rectal cancer is based upon wide anatomic resection. Ann Surg 1979;190:350-360.

-3 McAnena OJ, Heald RJ, Lockhart-Mummery HE: Operative and functional results of total mesorectal excision with ultra-low anterior resection in the management of carcinoma of the lower one-third of the rectum. Surg Gynecol Obstet 1990;170:517-521.

-4 Murty M, Enker WE, Martz J: Current status of total mesorectal excision and autonomic nerve preservation in rectal cancer. Semin Surg Oncol 2000;19:321-328.

5 Berends FJ, Kazemier G, Bonjer HJ, Lange JF: Subcutaneous metastases after laparoscopic colectomy. Lancet 1994;344:58.

-6 Heald RJ, Karanjia ND: Results of radical surgery for rectal cancer. World J Surg 1992;16: 848-857.

7 Kapiteijn E, van de Velde CJ: European trials with total mesorectal excision. Semin Surg Oncol 2000; 19:350-357.

8 Clinical Outcomes of Surgical Therapy Study Group: A comparison of laparoscopically assisted and open colectomy for colon cancer. N Engl J Med 2004;350:2050-2059.

-9 Leung KL, Kwok SP, Lam SC, Lee JF, Yiu RY, $\mathrm{Ng}$ SS, Lai PB, Lau WY: Laparoscopic resection of rectosigmoid carcinoma: prospective randomised trial. Lancet 2004;363:11871192.

10 MacFarlane JK, Ryall RD, Heald RJ: Mesorectal excision for rectal cancer. Lancet 1993; 341:457-460

11 Reynolds JV, Joyce WP, Dolan J, Sheahan K, Hyland JM: Pathological evidence in support of total mesorectal excision in the management of rectal cancer. Br J Surg 1996;83:11121115.

-12 Havenga K, DeRuiter MC, Enker WE, Welvaart $\mathrm{K}$ : Anatomical basis of autonomic nervepreserving total mesorectal excision for rectal cancer. Br J Surg 1996;83:384-388.

13 Dahlberg M, Glimelius B, Pahlman L: Changing strategy for rectal cancer is associated with improved outcome. Br J Surg 1999;86: 379 384.

14 Arbman G, Nilsson E, Halbook O, Sjodal R: Local recurrence following total mesorectal excision for rectal cancer. Br J Surg 1995; 18:375379.

15 Enker WE, Thaler HT, Cranor ML, Polyak T: Total mesorectal excision in the operative treatment of carcinoma of the rectum. J Am Coll Surg 1995;181:335-346.

- 16 Falk PM, Beart RW Jr, Wexner SD, Thorson AG, Jagelman DG, Lavery IC, Johansen OB, Fitzgibbon RJ Jr: Laparoscopic colectomy: A critical appraisal. Dis Colon Rectum 1993;36: $28-34$.
17 Monson JRT, Darzi A, Carey PD, Guillou PJ Prospective evaluation of laparoscopic-assisted colectomy in an unselected group of patients. Lancet 1997;340:831-833.

18 Musser DJ, Boorse RC, Madera F, Reed JF III: Laparoscopic colectomy: at what cost? Surg Laparosc Endosc 1994;4:1-5.

19 Braga M, Vignali A, Gianotti L, Zuliani W, Radaelli G, Gruarin P, Dellabona P, Di Carlo $\mathrm{V}$ : Laparoscopic versus open colorectal surgery: a randomized trial on short-term outcome. Ann Surg 2002;236:759-766.

20 Lacy AM, Garcia-Valdecasas JC, Delgado S, Castells A, Taura P, Pique JM, Visa J: Laparoscopy-assisted colectomy versus open colectomy for treatment of non-metastatic colon cancer: a randomised trial. Lancet 2002;359: 2224-2229.

21 Leroy J, Jamali F, Forbes L, Smith M, Rubino F, Mutter D, Marescaux J: Laparoscopic total mesorectal excision for rectal cancer surgery: long-term outcomes. Surg Endosc 2004; 18: 281-289.

22 Morino M, Parini U, Giraudo G, Salval M, Brachet Contul R, Garrone C: Laparoscopic total mesorectal excision: a consecutive series of 100 patients. Ann Surg 2003;237:335-342.

23 Marijnen CA, Kapiteijn E, van de Velde CJ, Martijn H, Steup WH, Wiggers T, Kranenbarg EK, Leer JW: Cooperative Investigators of the Dutch Colorectal Cancer Group. Acute side effects and complications after short-term preoperative radiotherapy combined with total mesorectal excision in primary rectal cancer: report of a multicenter randomized trial. J Clin Oncol 2002;20:817-825.

24 Morino M, Giraudo G: Laparoscopic total mesorectal excision - the Turin experience. Recent Results Cancer Res 2005;165:167-179.

25 Breukink SO, Pierie JP, Grond AJ, Hoff C, Wiggers T, Meijerink WJ: Laparoscopic versus open total mesorectal excision: a case-control study. Int J Colorectal Dis 2005;20:428-433.

26 Ramos JR, Petrosemolo RH, Valory EA, Polania FC, Pecanha R: Abdominoperineal resection: laparoscopic versus conventional. Surg Laparosc Endosc 1997; 7:148-152.

27 Bretagnol F, Lelong B, Laurent C, Moutardier V, Rullier A, Monges G, Delpero JR, Rullier E: The oncological safety of laparoscopic total mesorectal excision with sphincter preservation for rectal carcinoma. Surg Endosc 2005; 12. Epub ahead of print.

28 Carlsen E, Schlichting E, Guldvog I, Johnson E, Heald RJ: Effect of the introduction of total mesorectal excision for the treatment of rectal cancer. Br J Surg 1998;85:526-529.

29 Heald RJ, Moran BJ, Ryall RD, Sexton R, MacFarlane JK: Rectal cancer: the Basingstoke experience of total mesorectal excision, 19781997. Arch Surg 1998;133:894-899.
30 Kapiteijn E, Kranenbarg EK, Steup WH, Taat CW, Rutten HJ, Wiggers T, van Krieken JH, Hermans J, Leer JW, van de Velde CJ: Total mesorectal excision with or without preoperative radiotherapy in the treatment of primary rectal cancer. Prospective randomised trial with standard operative and histopathological techniques. Dutch Colorectal Cancer Group. Eur J Surg 1999;165:410-420.

- 31 Zaheer S, Pemberton JH, Farouk R, Dozois RR, Wolff BG, Ilstrup D: Surgical treatment of adenocarcinoma of the rectum. Ann Surg 1998;227:800-811.

32 Goldberg S, Klas JV: Total mesorectal excision in the treatment of rectal cancer: a view from the USA. Semin Surg Oncol 1998; 15:87-90.

-33 Karanjia ND, Corder AP, Bearn P, Heald RJ: Leakage from stapled low anastomosis after total mesorectal excision for carcinoma of the rectum. Br J Surg 1994;81:1224-1226.

- 34 Irvin TT, Goligher JC: Aetiology of disruption of intestinal anastomoses. Br J Surg 1973;60: 461-464.

35 Hallbook O, Pahlman L, Krog M, Wexner SD, Sjodahl R: Randomized comparison of straight and colonic $\mathrm{J}$ pouch anastomosis after low anterior resection. Ann Surg 1996;224:58-65.

36 Wu WX, Sun YM, Hua YB, Shen LZ: Laparoscopic versus conventional open resection of rectal carcinoma: a clinical comparative study. World J Gastroenterol 2004;10:1167-1170.

37 Zhou ZG, Hu M, Li Y, Lei WZ, Yu YY, Cheng Z, Li L, Shu Y, Wang TC: Laparoscopic versus open total mesorectal excision with anal sphincter preservation for low rectal cancer. Surg Endosc 2004; 18:1211-1215.

38 Quah HM, Jayne DG, Eu KW, Seow-Choen F: Bladder and sexual dysfunction following laparoscopically assisted and conventional open mesorectal resection for cancer. Br J Surg 2002; 89:1551-1556.

39 Weiser MR, Milsom JW: Laparoscopic total mesorectal excision with autonomic nerve preservation. Semin Surg Oncol 2000;19:396403.

40 Nagtegaal ID, Marijnen CA, Kranenbarg EK, van de Velde CJ, van Krieken JH: Pathology Review Committee; Cooperative Clinical Investigators. Circumferential margin involvement is still an important predictor of local recurrence in rectal carcinoma: not one millimeter but two millimeters is the limit. Am J Surg Pathol 2002;26:350-357.

41 Hartley JE, Mehigan BJ, Qureshi AE, Duthie GS, Lee PW, Monson JR: Total mesorectal excision: assessment of the laparoscopic approach. Dis Colon Rectum 2001;44:315-321.

42 Tsang WW, Chung CC, Li MK: Prospective evaluation of laparoscopic total mesorectal excision with colonic J-pouch reconstruction for mid and low rectal cancers. Br J Surg 2003;90: 867-871. 
43 Lord SA, Larach SW, Ferrara A, Williamson PR, Lago CP, Lube MW: Laparoscopic resections for colorectal carcinoma. A three-year experience. Dis Colon Rectum 1996;39:148154.

-44 Sobin LH, Greene FL: TNM classification: clarification of number of regional lymph nodes for pNo. Cancer 2001;92:452.

-45 Mohiuddin M, Regine WF, John WJ, Hagihara PF, McGrath PC, Kenady DE, Marks G: Preoperative chemoradiation in fixed distal rectal cancer: dose time factors for pathological complete response. Int $\mathrm{J}$ Radiat Oncol Biol Phys 2000;46:883-888.

-46 Decanini C, Milsom JW, Bohm B, Fazio VW: Laparoscopic oncologic abdominoperineal resection. Dis Colon Rectum 1994;37:552-558.
47 Pikarsky AJ, Rosenthal R, Weiss EG, Wexner $\mathrm{SD}$ : Laparoscopic total mesorectal excision. Surg Endosc 2002; 16:558-562.

48 Tomita H, Marcello PW, Milsom JW: Laparoscopic surgery of the colon and rectum. World J Surg 1999;23:397-405.

49 Stage JG, Schulze S, Moller P, Overgaard H, Andersen M, Rebsdorf-Pedersen VB, Nielsen HJ: Prospective randomized study of laparoscopic versus open colonic resection for adenocarcinoma. Br J Surg 1997;84:391-396.

50 Kim SH, Milsom JW, Gramlich TL, Toddy SM, Shore GI, Okuda J, Fazio VW: Does laparoscopic vs. conventional surgery increase exfoliated cancer cells in the peritoneal cavity during resection of colorectal cancer? Dis Colon Rectum 1998;41:971-978.
51 Havenga K, Enker WE, Norstein J, Moriya Y, Heald RJ, van Houwelingen HC, van de Velde CJ: Improved survival and local control after total mesorectal excision or D3 lymphadenectomy in the treatment of primary rectal cancer: an international analysis of 1,411 patients. Eur J Surg Oncol 1999;25:368-374.

52 Marescaux J, Leroy J, Gagner M, Rubino F, Mutter D, Vix M, Butner SE, Smith MK: Transatlantic robot-assisted telesurgery. Nature 2001;413:379-380.

53 Rubino F, Soler L, Marescaux J, Maisonneuve $\mathrm{H}$ : Advances in virtual reality are wide ranging. BMJ 2002;324:612.

54 Marescaux J, Rubino F, Arenas M, Mutter D, Soler L: Augmented-reality-assisted laparoscopic adrenalectomy. JAMA 2004;292:22142215 . 